\title{
Sanguinarine and Dihydrosanguinarine Accumulation in Argemone mexicana (L) Cell Suspension Cultures Exposed to Yeast Extract
}

\author{
Cecilia Guízar-González, Karen Trujillo-Villanueva, Miriam Monforte-González, and Felipe \\ Vázquez-Flota*
}

Unidad de Bioquímica y Biología Molecular de Plantas and Graduate Program in Biological Sciences, Centro de Investigación Científica de Yucatán, Calle 43 No. 130 Chuburna 97205 Mérida Yucatán. felipe@cicy.mx

Dedicated to Dr. Estela Sánchez de Jiménez for her valuable contributions to plant biochemistry

Received February 14, 2011; accepted April 20, 2011

\begin{abstract}
Alkaloid contents in Argemone mexicana cell line AMMiF were analyzed during a 36-day culture cycle. The benzophenanthridine sanguinarine (SA) represented the main alkaloid. Dihydrosanguinarine (DHSA), a SA biosynthetic precursor and a less toxic benzophenanthridine, was also identified, based on chromatographic properties and further confirmed by gas chromatography coupled to mass spectrometry. Along the culture cycle, SA contents increased simultaneously while DHSA decrease, suggesting their biosynthetic conversion. Upon exposure to yeast extract as an inducer of secondary metabolism, there was an increase in SA content, which was preceded by DHS accumulation. However, after a long exposure $(72 \mathrm{~h})$, contents of both SA and DHSA were noticeable elevated, with close to $20 \%$ of the total alkaloid produced being recovered from the external medium. These results suggest the operation of a cell mechanism to avoid damage inflicted by the excessive accumulation of SA.
\end{abstract}

Key words: Argemone mexicana, benzophenathridines, dihydrosanguinarine, sanguinarine.

\section{Introduction}

Argemone mexicana (L) (Papaveraceae) is a plant used in the Mexican traditional medicine. The healing properties of $A$. mexicana were presumably well known to ancient Mesoamerican cultures, prior to the arrival of Europeans [1]. The presence of a number of benzylisoquinoline alkaloids (BIA) may explain such medicinal effects. For example, the benzophenanthridines sanguinarine (SA) and dihydrosanguinarine (DHSA) display antimicrobiae and cytotoxic activities. These alkaloids are accumulated in roots and mature seeds, whereas berberine, a protoberberine alkaloid with antiviral properties, is accrued both in aerial and underground tissues [2]. The toxic nature of these compounds suggests an ecological role in the chemical defense against herbivores [3]. BIA's are formed from two units of tyrosine which after a series hydroxylation, deamination and decarboxylation reactions, are condensed into norcoclaurine. Further enzymatic reactions transform this intermediary into the benzophenanthridines alkaloids [4]. In accordance to their protective role, the biosynthesis of BIA's is transcriptionally activated in response to environmental injury and this has been applied with biotechnological purposes to increase alkaloid production in in vitro cell cultures [5]. These cultures exposed to conditions mimicking a pathogenic attack increase SA biosynthesis
Resumen. Los contenidos de alcaloides en cultivos celulares de Argemone mexicana, línea $\mathrm{AMMiF}$, fueron analizados a lo largo de un ciclo de 36 días. Se encontró que la benzofenantridina sanguinarina (SA) fue el alcaloide principal. La dihidrosanguinarina (DHSA), precursor biosintético de la SA y una forma menos tóxica, también fue identificada con base en sus propiedades cromatográficas y confirmada por cromatografía de gases acoplada a espectrofotometría de masas. A lo largo del ciclo de cultivo, los contenidos de SA aumentaron mientras los de DHSA disminuyeron, lo que sugiere la interconversión biosintética. Tras la exposición al extracto de levadura, como inductor del metabolismo secundario, se observó un aumento en el contenido de $\mathrm{SA}$, que fue precedido por la acumulación de DHSA. Sin embargo, después de una larga exposición (72 h), los contenidos de SA y DHSA fueron notablemente elevados, recuperándose cerca del $20 \%$ del total de los alcaloides del medio externo. Estos resultados sugieren la operación de un mecanismo celular para reducir los daños ocasionados por la acumulación excesiva de DHSA.

Palabras clave: Argemone mexicana, benzofenantridinas, dihidrosanguinarina, sanguinarina.

and some portion of it is excreted to the external medium [6]. Furthermore, part of this newly synthesized SA is reduced to the less toxic DHSA suggesting the operation of an enzymatic detoxification mechanism [6,7]. We have an A. mexicana cell suspension culture, namely $\mathrm{AMMiF}$, which produces significant amounts of SA and DHSA, even without any induction treatment [7]. Interestingly, SA accumulation increased when DHSA decreased, implying the conversion of one into the other. Upon induction with yeast extract, the accumulation of both SA and DHSA increased, although in a limited fashion in comparison to cultures of other SA producing species [7] and also following different patterns, which may point to the operation of a cellular mechanism to avoid damage from an excessive accumulation of SA.

\section{Results}

Alkaloids were extracted from A. mexicana cell suspensions and analyzed by TLC. Under UV long wavelength light (365 $\mathrm{nm}), \mathrm{SA}$ was identified by its red-orange fluorescence at $\mathrm{Rf}$ 0.70 , identical to the standard. A second red-orange fluorescent spot at Rf 0.89 was also recorded (Fig. 1). Fluorescence properties suggest that this compound was a benzophenanthridine. 


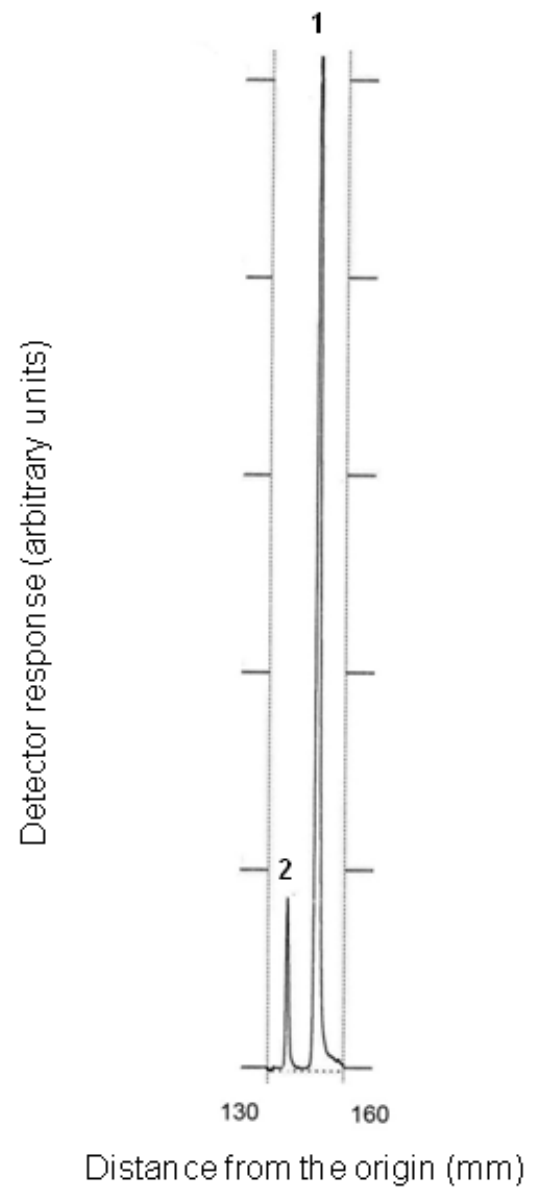

Fig. 1. TLC chromatoscan showing the presence of sanguinarine (1) and dihydrosanguinarine (2) in extracts from the Argemone AMMiF cell line.

Besides SA, other benzophenantrhridines have been identified in A. mexicana tissues, mainly DHSA, chelerythrine, dihydrochelerythrine and chelidoline [2]. In order to assign an identity to this unknown compound, extracts were analyzed by GC-MS. The unknown compound and SA resolved at $t_{\mathrm{R}}$ of 14.732 and $16.731 \mathrm{~min}$, respectively. Mass spectra of the unknown compound $\mathrm{m} / \mathrm{z} 333[\mathrm{M}+](86), 332$ (100), 318 (5), 317 (4), 203 (15), corresponded to DHSA, whereas that of SA $\mathrm{m} / \mathrm{z} 332[\mathrm{M}+]$ (5), 317 (100) 258 (8); 290 (46), was similar to the standard and as has been previously reported [9]. Therefore, based on MS data, and the well known metabolic interconversion between SA and DHSA [6], the unknown benzophenanthridine was identified as DHSA.

Along the first phase of a culture cycle, DHSA contents decreased while those of SA steadily increased to a maximum, nearing to $14 \mathrm{nmol} \mathrm{g} \mathrm{DW}^{-1}$. Interestingly, maximal SA content was attained simultaneously to DHSA lowest contents (near to $6 \mathrm{nmol} \mathrm{g} \mathrm{DW}^{-1}$; Fig. 2). SA is the result of DHSA oxidation; hence, these results indicate that the biosynthetic pathway leading to sanguinarine formation is fully active in the AMMiF cell line.

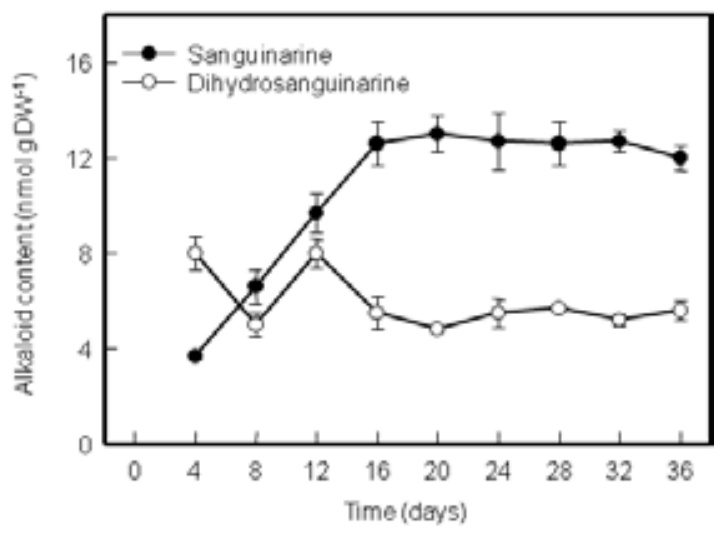

Fig. 2. Sanguinarine and dihydrosanguinarine accumulation in the AMMiF A. mexicana cell line along a 36-day culture cycle. Average of triplicates with standard deviation.

In order to induce alkaloid accumulation, Argemone cell suspensions were exposed to yeast extract $\left(200 \mathrm{mg} \mathrm{L}^{-1}\right)$. This dose probed to be the most effective [8]. Prior to cell exposure, SA was the prominent alkaloid with little DHSA found. During the first $24 \mathrm{~h}$ of exposure, DHSA content increased markedly (from 0.7 to $32 \mathrm{nmol} \mathrm{g} \mathrm{DW}^{-1}$; i.e a 42 -fold increase), whereas the initial SA contents only increased around 2.5-fold (from 7 to $19 \mathrm{nmol} \mathrm{g} \mathrm{DW}^{-1}$ ). However, after $48 \mathrm{~h}$ DHSA returned to its initial values, while SA amounts remained at a similar level, and after $72 \mathrm{~h}$, both SA and DHSA presented similar amounts. It is noteworthy to mention that a significant amount of SA was recovered from the spent medium, but no DHSA was detected (Table 1).

\section{Discussion}

Successful plant chemical defense requires a delicate balance involving production of noxious compounds in amounts enough to repel herbivore or pathogen attack while preventing their toxic effects in the cells that produces or accumulates them. Through the course of evolution, different mechanisms have developed to achieve this goal, including the sequestering of toxic compounds in vesicles, their chemical modification to less toxic forms, readily reconverted to the more active forms when required, and their excretion [10]. SA displays a cationic nature which allows it to bind to the negatively charged membranes and proteins, interfering with their functioning. The reduction of SA to its dihydro form diminishes these effects, resulting in a less toxic compound [6]. The first response to YE elicitation of the Argemone AMMiF cell line involved a pronounced accumulation of DHSA, with little effect on SA levels (Table 1). Since DHSA is the precursor of SA in the biosynthetic pathway (Fig. 1), this result suggests, that at these early phases of induction, DHSA concentration in the cell built up prior its oxidation to SA. As the response progressed, DHSA was transformed into SA, which then was apparently excreted (Table 1; $48 \mathrm{~h}$ ), preventing in this way its possible toxic effects. At longer periods, 
Table 1. Sanguinarine (SA) and dihydrosanguinarine (DHSA) contents in the cell package and spent medium of the AMMiF $A$. mexicana cell line elicited with yeast extract. Average of triplicates with standard deviation between brackets. ND, not detected.

\begin{tabular}{|c|c|c|c|c|}
\hline \multirow{3}{*}{$\begin{array}{l}\text { Time of } \\
\text { exposure } \\
\text { (h) }\end{array}$} & \multicolumn{2}{|c|}{ Cell package } & \multicolumn{2}{|c|}{ Spent medium } \\
\hline & SA & DHSA & SA & DHSA \\
\hline & \multicolumn{2}{|c|}{$\mathrm{nmol} \mathrm{g} \mathrm{DW}^{-1}$} & \multicolumn{2}{|c|}{$\mathrm{nmol} 50 \mathrm{~mL}^{-1}$} \\
\hline 0 & $7(0.71)$ & $0.7(0.4)$ & $0.23(0.12)$ & ND \\
\hline 24 & $19(0.72)$ & $32(2.8)$ & $1.1(0.4)$ & ND \\
\hline 48 & $16(1.2)$ & $3(0.5)$ & $5.5(0.9)$ & ND \\
\hline 72 & $11(0.83)$ & $12(1.3)$ & $12(1.3)$ & ND \\
\hline
\end{tabular}

when the maximal response was reached (Table 1; $72 \mathrm{~h}$ ), it appeared that either the rate of DHSA oxidation to SA decreased, or that SA was reduced back to DHSA (Fig. 1). Interestingly, only SA, but not DHSA, was recovered from the medium, and in substantially lesser amounts than those extracted from the cell package (Table 1). In an alternative manner, SA could also have been degraded. Chromatographic analysis revealed the presence of putative benzophenanthridines, which could not be identified due to their unstable nature. The formation of these unstable, short-lived, products has been previously observed [6]. Finally, such response suggests the operation of a mechanism to cope with the deleterious effects of SA inside the cell [7], which involves the control of the internal amounts of the oxidized form by reducing it to DHSA, and/or excreting it to the external medium.

\section{Conclusion}

In $A$. mexicana cell suspension cultures, the toxic effects of a high benzophenanthridine accumulation, induced by YE, are managed through reducing the internal contents of the oxidized (SA) to the less toxic dihydro (DHSA) forms or its excretion to the medium.

\section{Experimental section}

Biological materials. The Argemone mexicana cell line AM$\mathrm{MiF}$ has been maintained through biweekly subcultures in PC-BN medium (inorganic salts and vitamins of Phillips and Collins medium, supplemented with 0.5 and $1.5 \mathrm{mg} \mathrm{L}^{-1}$ of benzyladenine and naphtalenacetic acid, respectively and 20 $\mathrm{g} \mathrm{L}^{-1}$ of sucrose [8]. For the culture cycle, $5 \mathrm{~mL}$ of a 14-day old cell suspension (representing between 0.20 and $0.22 \mathrm{~g} \mathrm{FW}$ $\mathrm{mL}^{-1}$ were transferred to $250 \mathrm{~mL}$ Erlenmeyer flasks, containing $50 \mathrm{~mL}$ of the PC-BN medium and maintained for up to 30 days, taking samples by triplicate as indicated in the Figures. Sanguinarine biosynthesis was induced with $200 \mathrm{mg} \mathrm{L}^{-1}$ yeast extract (YE; Sigma-Aldrich, St. Louis MO). Briefly, 10 dayold cultures received $1.0 \mathrm{~mL}$ of a YE solution, previously filter sterilized through a $0.2 \mu \mathrm{m}$ pore size nylon sterile membrane (Corning, NY), to render the desired concentration [8]. Controls were mock induced with water. Samples, by triplicate, were collected as indicated in Figures, recording growth as fresh weight prior to freezing them in liquid nitrogen.

Analytical procedures. Alkaloids were extracted from freeze dried tissues with $\mathrm{HCl} 0.5 \%$ in methanol (v/v). Between 100 and $150 \mathrm{mg}$ of ground tissues were incubated at $45^{\circ} \mathrm{C}$ with gently shaking for $2 \mathrm{~h}$. Cell debris was removed by filtration and the acidic extract was reduced to dryness at low pressure. Residue was dissolved in $1 \mathrm{~mL}$ of methanol and alkaloids were separated by thin layer chromatography (TLC), using as mobile phase a benzene/ethanol ( $9 / 1$ by vol.) mixture. SA and DHSA were quantified by in situ fluorescence (325 and $545 \mathrm{~nm}$ for excitation and emission, respectively) using a Shimadzu CS-930 dual wavelength chromatoscanner, equipped with a DR 2 data collector (Kyoto Japan). Alkaloid identity was assigned based on Rf's values, and further confirmed by gas chromatography coupled to mass spectroscopy (GC-MS). GC-MS was carried out in an Agilent Technologies $6890 \mathrm{~N}$ gas chromatographer coupled to a 5975B mass detector, using a glass capillary column $(25 \mathrm{~m} \times 0.32 \mathrm{~mm}$ i.d $\times 30 \mu \mathrm{m})$. Nitrogen was used as carrier gas at a flow rate of $45 \mathrm{~mL} \mathrm{~min}^{-1}$. Injector and detector temperatures were set at 150 and $300{ }^{\circ} \mathrm{C}$, respectively. Initial column temperature was $80{ }^{\circ} \mathrm{C}$, then increased to $300{ }^{\circ} \mathrm{C}(2$ $\mathrm{min})$, and finally kept at $300{ }^{\circ} \mathrm{C}(10 \mathrm{~min})$. Alkaloids were identified comparing fragmentation patterns to those previously reported [9].

\section{Acknowledgments}

This work was supported by Consejo Nacional de Ciencia y Tecnología (CONACYT, grant P60746) and The Academy of Sciences for the Developing World (TWAS), 06-177 RG/BIO/ LA-UNESCO FR:3240157854TWAS. CG-G is recipient of a CONACYT scholarship for doctoral studies. The authors wish to thank Dr. M.L. Miranda Ham for her critical review of the manuscript, as well as Silvia Andrade and Dr. L.M. Peña-Rodríguez for their assistance in the GC-MS analysis and data interpretation.

\section{References}

1. Reyna Robles, R.M.; González Quintero L. Arqueobotanica 1978, 63, 33-41.

2. Chang, Y.C.; Chang, F.R.; Khalil, A.T.; Hsieh, P.W.; Wu, Y.C. $Z$ Naturforsch [C] 2003, 58, 521-526.

3. Cho, H.Y.; Lee-Parson, S.Y.; Yoon, S.Y.H.; Rhee, H.S.; Park, J.M. Biotechnol. Lett. 2007, 29, 2001-2005.

4. Ziegler, J.; Facchini, P. Ann Rev Plant Biol 2008, 59, 735-769.

5. Eilert, U.; Kurz, W.G.W.; Constabel, F. J. Plant Physiol. 1985, 119, 65-76.

6. Weiss, D.; Baumert, A.A.; Vogel M.; Roos, W. Plant Cell Environ 2006, 29, 291-302.

7. Trujillo-Villanueva, K.; Rubio-Piña, J.; Monforte-González, M.; Vázquez-Flota, F. Biotechnol Lett 2010, 32, 1005-1009. 
8. Vázquez-Flota, F.; Monforte-González, M.; Guízar-González, C.; Rubio-Piña, J.; Trujillo-Villanueva, K., in: Plant Cell Culture Protocols Third Edition, Loyola-Vargas, V.; Ochoa-Alejo, N., Eds., Humana Press Totowa N.J., In press.
9. Pérez-Gutiérrez, R.M.; Vargas-Solís, R.; Díaz-Gutiérrez, G.; Martínez-Martínez F.J. Phytochem. Anal. 2002, 13, 177-180.

10. Bennett, R. N. and Wallsgrove R. M. New Phytol. 1994, 127, 617633. 